
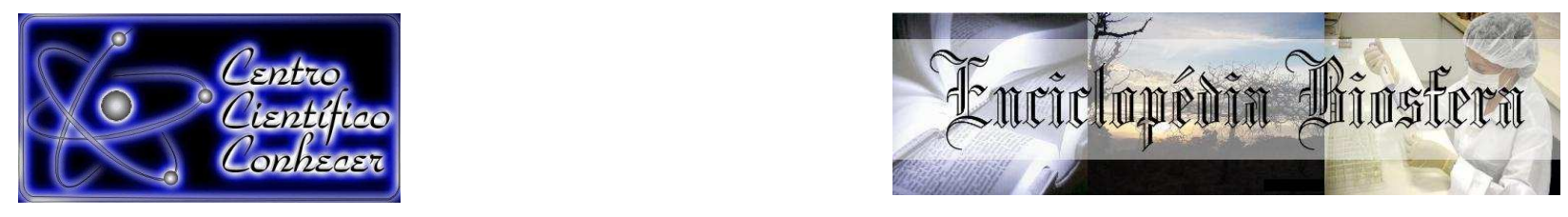

\title{
USO DO PROGRAMA POWER POINT COMO FERRAMENTA NA DISCIPLINA DE BIOLOGIA - BOTÂNICA DO ENSINO MÉDIO NA CIDADE DE CAXIAS, MARANHÃO
}

Samuel da Silva Carvalho', Guilherme Sousa da Silva², Maria Lindalva Alves da Silva $^{3}$, Gonçalo Mendes da Conceição ${ }^{4}$

1 Graduando do Curso de Ciências Biológicas Licenciatura do Centro de Estudos

Superiores de Caxias da Universidade Estadual do Maranhão (sa-

musi@hotmail.com)

2. Graduado do Curso de Ciências Biológicas Licenciatura do Centro de Estudos

Superiores de Caxias da Universidade Estadual do Maranhão

3. Mestranda do Programa de Pós-Graduação em Biodiversidade, Ambiente e

Saúde/PPGBAS, do CESC/UEMA

4. Professor Doutor da Universidade Estadual do Maranhão do Programa de PósGraduação em Biodiversidade, Ambiente e Saúde-PPGBAS, Caixa Postal 027

Teresina/Piauí-Brasil

Recebido em: 08/04/2016 - Aprovado em: 30/05/2016 - Publicado em: 20/06/2016 DOI: 10.18677/Enciclopedia_Biosfera_2016_161

\begin{abstract}
RESUMO
A prática educacional possibilita aos educandos desenvolver habilidades que proporcionem um ensino contextualizado, contribuindo para melhoria da qualidade no ensino. Neste contexto, os recursos midiáticos oportunizam um dinamismo nas aulas que muitas vezes, são ministradas apenas com apoio do livro didático, sem nenhuma outra metodologia. Dessa forma, o trabalho tem a finalidade de utilizar os recursos audiovisuais através do programa Power Point para subsidiar a disciplina de Biologia, com ênfase em Botânica em escolas do Ensino Médio da cidade de Caxias/MA. Para a realização do trabalho, foi selecionada à escola Centro de Ensino Cônego Aderson Guimarães Junior, instituição de ensino médio que atende a 710 alunos do município. Para a realização da pesquisa, inicialmente foi feito um levantamento bibliográfico e posteriormente a obtenção de fotos de estruturas vegetais para apresentação em slides didáticos, com a adição de tópicos e esquemas, para elucidar o conteúdo ministrado. As aulas foram ministradas através do uso do recurso midiático Datashow e ministradas no período de fevereiro a março de 2016. Com aplicação das aulas, demonstraram-se pontos positivos e negativos, mas verificou-se o aprimoramento da aprendizagem, superando várias lacunas deixadas apenas pelo ensino teórico. Em todas as apresentações houve a interação das imagens com esquemas, buscando trazer o conteúdo teórico à realidade dos alunos, permitindo assim a criação de um espaço educativo e atrativo para aprendizagem de botânica. Este trabalho mostrou-se importante, pois torna 0 conhecimento mais lúdico, facilitando o acesso a aprendizagem do aluno.
\end{abstract}

PALAVRAS-CHAVE: Educação, Ensino de Biologia, Multimídias. 


\title{
POWER POINT PROGRAM AS A TOOL USE IN BIOLOGY OF DISCIPLINE - SECONDARY EDUCATION IN THE BOTANICAL CAXIAS CITY, MARANHÃO
}

\begin{abstract}
The educational practice enables students to develop skills that provide a teaching contextualized contributing to improving the quality of education. In this context the media resources nurture a dynamism in the classes are often taught only with the support of the textbook without any other methodology. Due to this problem, it is proposed that this work in order to use audiovisual resources via the Power Point program to support the Biology discipline with emphasis in botany in high school schools in Caxias-MA. For the realization of the project was chosen to school Cônego Education Center Aderson Guimarães Junior, high school institution that serves 710 students in the municipality. To carry out the work was done a literature and later obtaining photos of plant structures for didactic presentation slides with the addition of topics and schemes, to clarify the content taught. The classes were effective through the use of the media resource power point and held from February to March 2016. With the application of the lessons proved to be positives and negatives, but there was an improvement of learning, overcoming several gaps left only the theoretical. In all presentations was the interaction of images with schemes seeking to bring the theoretical content to the reality of students, thus allowing the creation of an educational and attractive space for learning botany. This project shows is important because it makes the most playful knowledge and facilitates access to student learning.
\end{abstract}

KEYWORDS: Education, Biology Education, Multimedia.

\section{INTRODUÇÃO}

O Sistema Educacional no Brasil após aprovação da Lei de Diretrizes e Bases da Educação Nacional - LDB no 9.394/96 provocou mudanças no processo ensino-aprendizagem, quanto ao uso de metodologias para serem aplicadas em sala de aula, que não se concebe que um profissional da educação ainda utilize o método tradicional, pois hoje os docentes contam com vários recursos que podem ajudá-los numa metodologia de ensino mais dinâmico e com maior interação entre alunos e professores (BRASIL, 1996).

O ensino de Ciências e a formação dos docentes da área, ao longo do tempo vêm passando por múltiplas influências no que se refere à tradição escolar, as orientações curriculares, os documentos oficiais e os livros didáticos, o que a torna um campo complexo de estudos e investigações (FRISON et al., 2012). No Ensino Médio, a última etapa da educação básica, precisa-se de uma atenção especial, pois os alunos estão sendo formados para atuarem no mercado de trabalho e necessitam que os conteúdos sejam abordados com metodologias que tenham significância e aplicabilidade na sociedade em que estão inseridos. Neste contexto, desde a existência do homem os recursos tecnológicos modificam a forma de viver de grande parte da humanidade e este passa a agir sobre a natureza, modificando a forma de viver das pessoas através da criação de diferentes recursos e tecnologias (BRASIL, 1996; SANTOS, 2006).

Esse conceito de um ensino investigativo, experimental e midiático de ciências não é novo, pois há tempo já tem sido propalado e utilizado por educadores e pesquisadores em todo o mundo (BRASIL, 2014). A cada dia os avanços tecnológicos têm se mostrado impactantes no cenário social levando a diversas 
transformações. Rotineiramente procura-se manuseá-los pois estes acabam por modificar a forma de relacionar-se socialmente, de comunicar-se, consequentemente, de educar (KENSKI, 2010; MORAN, 2013). Sendo assim, diversos recursos podem ser utilizados nas aulas, principalmente de ciências, sejam estas dialogadas, expositivas ou experimentais (MARTINS et al., 2010).

Dentro das várias vertentes da Educação, o ensino de Biologia, especificamente o de Botânica apresenta várias dificuldades, pois a maioria dos professores demonstra descaso, fazendo com que os alunos não compreendam os conteúdos e na maioria das vezes apresentem uma aversão ao conhecimento (MELO et al., 2012). Os modelos de educação vigentes ainda estão focados no ensino tradicional, principalmente, como o professor ministra as aulas. A presença das tecnologias na educação requer dos professores, coordenadores e gestão uma nova postura, uma abertura a integração das mídias no contexto educacional (SILVA, 2013).

De acordo com os Parâmetros Curriculares Nacionais (BRASIL, 1998), novas tecnologias da comunicação e da informação (TICs) permeiam o cotidiano, independente do espaço físico, e criam necessidades de vida e convivência que precisam ser analisadas no espaço escolar. $O$ desenvolvimento crescente das (TICs) e seu uso no meio didático-pedagógico têm provocado vastas mudanças na sociedade atual e sobretudo, no meio acadêmico (GAMA; TAVARES, 2014).

Nessa perspectiva, os recursos audiovisuais são relevantes no contexto educacional. Dentre estes pode-se citar o do Microsoft Office Power Point como instrumento de apoio metodológico que auxilia o professor na sala de aula. É um dos programas utilizados pelos alunos e professores, o banco de pacote do Microsoft Office Power Point, que além de ser considerado uma ferramenta bastante eficaz nos trabalhos voltados a aprendizagem nas escolas públicas, se destaca por ser um programa gratuito e de fácil acessibilidade. Possui mecanismos normalmente não utilizados ou esquecidos pelos usuários, como os hiperlinks e hipermídias, mas quando utilizados na confecção de slides podem criar um espaço atrativo que leve os alunos a se sentirem bem no decorrer da exposição do conteúdo, possibilitando interação entre o mundo virtual e o real, outro ponto positivo nesta ferramenta é o fato de se poder criar espaços antes meramente descritivos, que levem o aluno ao mundo antes visto somente nos livros didáticos ou em figuras, tornando assim o conhecimento mais próximo destes mediante a interação deste recurso (JUNIOR; BARROS, 2005; MICROSOFT, 2013).

A educação, antes do surgimento tecnológico, já visava a agregação de valores aos conhecimentos produzidos e divulgados em sala de aula, com as tecnologias a mesma teria uma contribuição qualitativa que levaria a um crescimento participativo e crítico das capacidades do aluno (SILVA \& CORREIA, 2014). O uso de recursos audiovisuais como do programa Power Point na disciplina de Biologia mostra a eficácia como uma ferramenta que contribui no melhor entendimento do ensino. Porém, na maioria dos casos os professores encontram dificuldades no acesso destes programas, segundo SANDERS \& SAUER (2014) os diversos meios tecnológicos existentes são utilizados por diferentes segmentos educacionais para aperfeiçoar o processo de ensino e aprendizagem. Tais tecnologias precisam de estudos onde os professores possam utilizá-las com segurança, junto aos alunos.

Por essa ótica faz-se necessário que o professor crie oportunidades para que a aprendizagem resulte de um processo de construção de conhecimento, dos valores neles impregnados e da necessária reflexão acerca da avalanche informacional que vem sendo proporcionada pelos meios tecnológicos (SILVA, 
2013). Em virtude desta problemática no âmbito educacional este trabalho foi proposto com a finalidade de mostrar a importância da utilização de recursos audiovisuais através do Power Point para subsidiar o ensino de Biologia, com ênfase em conteúdos relacionados à Botânica em escolas do Ensino Médio da cidade de Caxias/Maranhão.

\section{MATERIAL E MÉTODOS}

Para realização do trabalho, foi necessário inicialmente leitura e consulta de artigos, teses, dissertações, livros, periódicos, entre outros meios. Após a revisão literária, foram selecionados conteúdos na área de Botânica, os quais foram ministrados em sala de aula, com temas relacionados a grade curricular do ensino médio: Briófitas, Pteridófitas, Gimnosperma, Angiosperma, Morfologia e Fisiologia Vegetal de acordo com o livro didático adotado pela escola. A preparação dos conteúdos se deu nos meses de setembro a novembro de 2015 e a obtenção das imagens e montagem dos slides, nos meses de setembro de 2015 a fevereiro de 2016, para a aquisição das fotos, foram selecionados locais estratégicos para fotografar as estruturas e os espécimes vegetais da própria cidade de Caxias/MA, como a Praça Duque de Caxias, balneário Veneza e Parque da Cidade (Fig. 1), e como em demais locais que mostrassem uma visão concreta dos conteúdos botânicos a serem ministrados. As fotos foram preferencialmente obtidas de espécies vegetais cosmopolitas, buscando criar um vínculo entre o alunado e as plantas localizadas na comunidade, evitando ao máximo a utilização de imagens de outras fontes como internet, revistas, livros, etc.

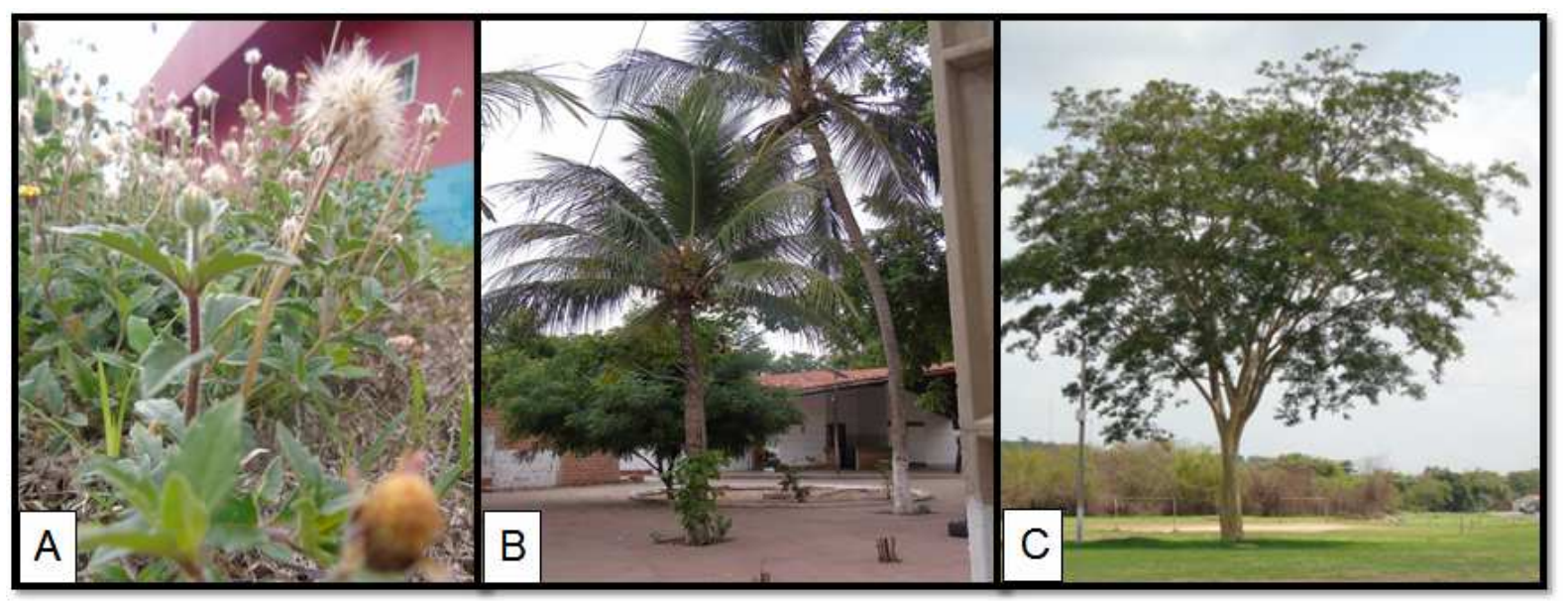

FIGURA 1. Locais de obtenção de Fotos para Confecção dos Slides. A. Jardim da Balaiada, Praça Duque de Caxias. B. Coqueiro do Balneário Veneza. C. Arvore do parque da cidade. Fonte: CARVALHO, S. S. 2016.

No total, aproximadamente 210 imagens foram obtidas, onde apenas as mais nítidas e com melhor foco das estruturas foram adicionadas aos slides, após a obtenção das imagens dos espécimes vegetais, a montagem dos slides foi efetuada com criatividade e linguagem fácil para melhor compreensão dos alunos, através da utilização do programa Microsoft Office Power Point e suas ferramentas multimídias que permitem a adição e organização de fotos, áudios, hiperlinks, entre outros instrumentos (Fig. 2). 


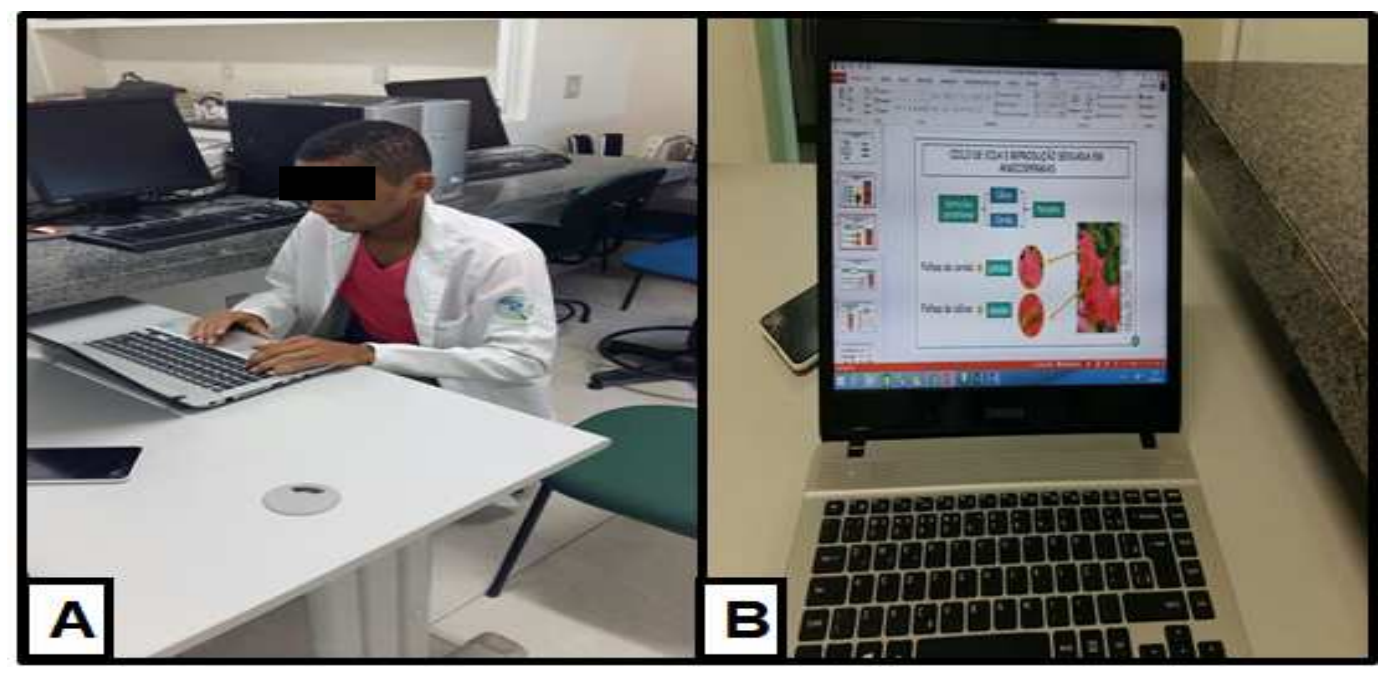

FIGURA 2. Montagem e Preparação dos Slides. A. Confecção das aulas. B. Edição das fotos através do Power Point. Fonte: SILVA, G. S. 2016.

\section{$\mathrm{P}$}

ara a realização do projeto, foi selecionada a escola: Centro de Ensino Cônego Aderson Guimarães Junior, instituição de ensino médio que pertence a rede estadual, que atende a 710 alunos. A escola está sediada no Centro Urbano de Caxias/MA (Fig. 3). Foi selecionada uma turma de $3^{\circ}$ ano da escola, contendo 35 alunos matriculados, onde na grade curricular estão inseridos os conteúdos de botânica. As aulas foram ministradas através do uso do recurso midiático Datashow, no período de fevereiro a março de 2016, com aulas planejadas e organizadas previamente, totalizando 27 horas aulas, com tempo de duração entre 25 a 45 minutos de exposição dos conteúdos. Com aplicação de avaliação composta por dez questões fechadas sobre os conteúdos de botânica ministrados.
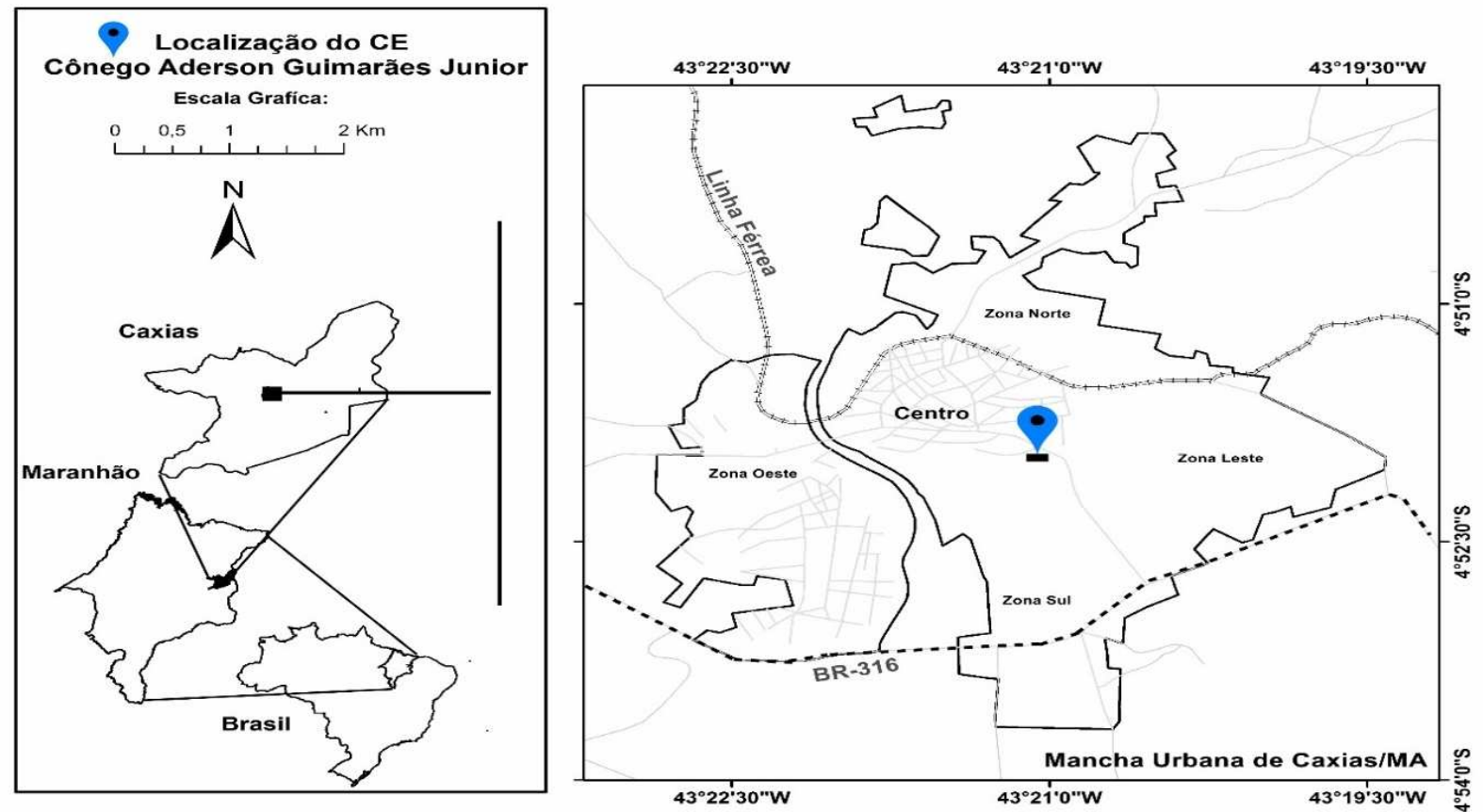

FIGURA 3. A. Mapa da localização do Brasil, Maranhão, Caxias. B. Zona Urbana de Caxias, em azul o ponto marcando a localização do C.E. Cônego Aderson Guimarães. Fonte: NOBRE, W. F. 2016. 


\section{RESULTADOS E DISCUSSÃO}

As aulas foram ministradas e inicialmente percebeu-se um impacto nos alunos, pois os mesmos não estavam familiarizados com aulas que utilizem recursos midiáticos. A utilização do Datashow, torna a exposição dos conteúdos mais interessante, percebendo-se o envolvimento dos alunos durante a apresentação do material, com a atenção dos alunos gera-se uma ampliação do conhecimento pois o interesse pelo conteúdo apresentado leva a fixação do aprendizado. SOUSA et al., (2012) trabalhando com 15 alunos do $3^{\circ}$ ano do ensino fundamental ao mediar o conteúdo sobre Regiões do País e as Zonas da cidade de Teresina, através dos recursos midiáticos como Power Point, foi possível notar um maior envolvimento por partes dos discentes, onde os mesmos se sentiram mais atraídos a exposição dos conteúdos.

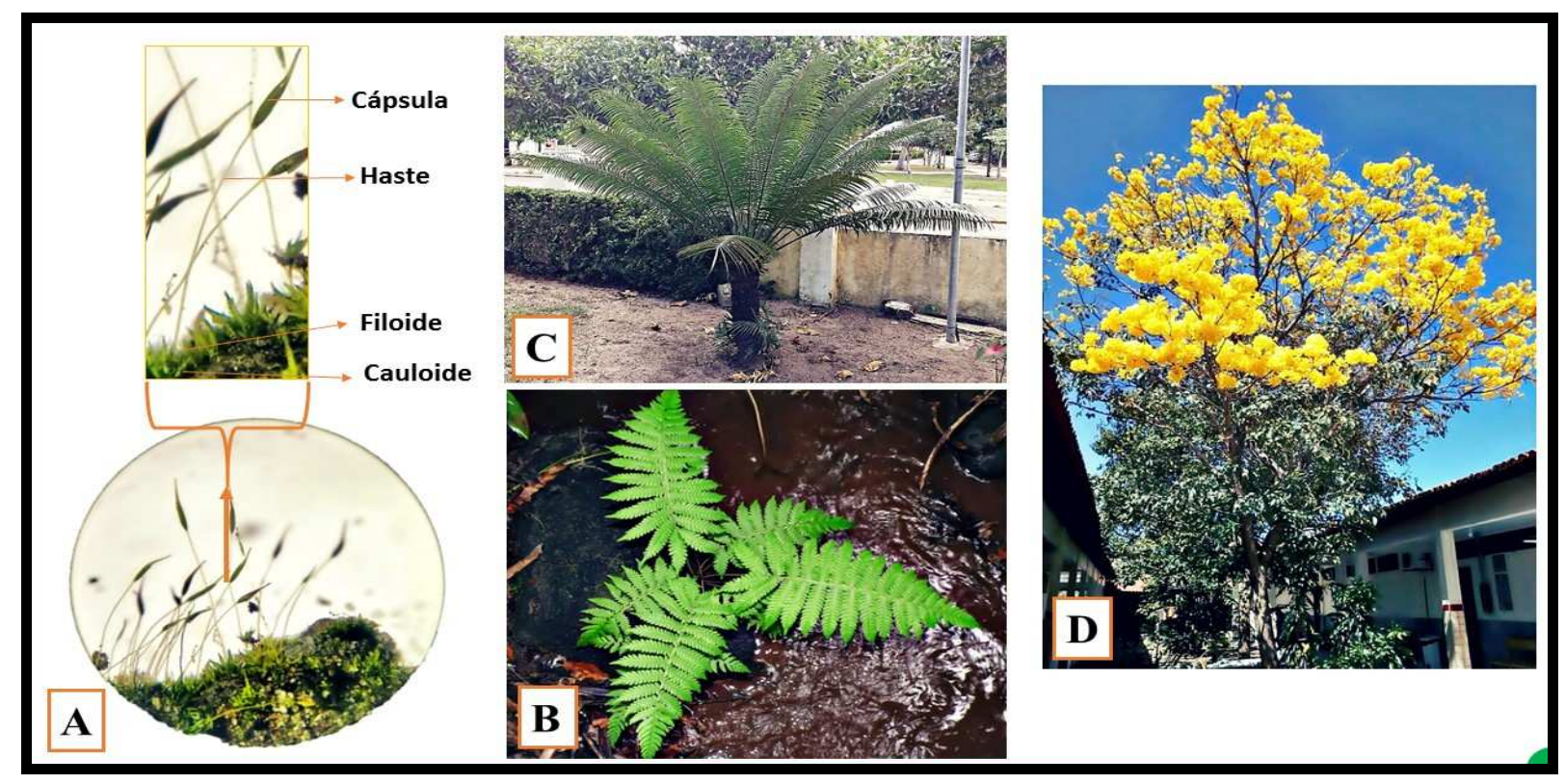

FIGURA 4. Representações dos principais grupos de plantas. A. Briófita (Musgo). B. Pteridófitas (Samambaia). C. Gimnospermas (Pinho). D. Angiospermas (Ipê-Amarelo). Fonte: CARVALHO, S. S. 2016.

Com o decorrer das aulas de botânica com a utilização dos recursos midiáticos, vários pontos negativos foram observados como 0 fato dos alunos mostrarem-se desinteressados, pois alguns alunos conversavam bastante, mas gradativamente os mesmos iam se familiarizando com os conteúdos prestando mais atenção ao que era desenvolvido. O desinteresse observado na exposição das aulas de botânicas é respondido e também notado nos trabalhos de SILVA et al., (2011) que ao fazerem um levantamento com alguns docentes de Biologia de escolas públicas e privadas de Imperatriz/MA, observaram que para os docentes $45 \%$ destes apontavam a falta de interesse dos alunos como sendo uma das grandes dificuldades encontradas para lecionar a Botânica em aulas práticas.

Outras dificuldades foram encontradas durante a exposição dos conteúdos, como o fato das terminologias dos grupos vegetais serem difíceis de pronunciar e por conterem algumas palavras científicas de forma não usual pelos alunos, o que prejudicava a absorção do conhecimento. SILVA et al., (2014) apontam essa problemática ao trabalhar com alunos do ensino médio, onde sentiram dificuldades ao iniciar a apresentação das aulas, posteriormente a inclusão de estruturas 
vegetais juntamente com a exposição dos conteúdos mostrou que tal dificuldade é minimizada.

Segundo MELO et al., (2012) os alunos demonstram muitas dúvidas e dificuldades na compreensão dos ciclos reprodutivos dos grupos vegetais, estes discentes também alegaram que os entraves estavam relacionados ao fato dos conteúdos estarem cheios de nomes e etapas de difícil compreensão, estas afirmações são respondidas pelo fato de $60 \%$ dos alunos entrevistados mostraremse adversos, gostando pouco ou até não gostando das aulas.

Outro fato constatado nas aulas, foi à falta de concentração de alguns alunos, pois constantemente o professor tinha que interromper as aulas em virtude dos alunos utilizarem o celular em sala de aula, TIMBANE et al., (2015) ressaltam que a utilização do celular no ambiente escolar é uma ferramenta muito útil enquanto recurso didático, todavia é o "vilão" do déficit de atenção dos discentes e do baixo desempenho pedagógico, pois o verdadeiro foco de aprendizagem não é atingido em virtude dos alunos realizarem atividades paralelas as que foram propostas em sala de aula. SOUSA et al., (2012) também salientam que a inserção midiática auxilia os alunos com déficit de concentração. Avaliando alunos submetidos aos recursos audiovisuais os autores perceberam que estes tornaram-se mais concentrados e se sentiram incentivados facilitando o processo de ensinoaprendizagem e fixação dos conteúdos.

Dentre vários pontos positivos extraídos da dinâmica do projeto, um dos pontos foi a aplicação do mesmo na escola, pois a mesma ainda não tinha nenhum projeto com essa temática, assim a escola, professor e alunos sentiram-se privilegiados por servir de campo de conhecimento e também por aprimorarem suas estratégias pedagógicas, deixando claro o que SILVA et al., (2015) apresentam como uma notória importância quanto ao uso de modalidades didáticas, ressaltando que através da fusão do conhecimento teórico e prático ocorra um envolvimento entre ensino aprendizagem e construção do conhecimento sociocultural.

Um importante ponto positivo do projeto foi a diferença no ensinoaprendizado, pois a forma teórica de ensinar, apesar de ser tradicional, gera várias lacunas para que o aluno possa desenvolver o conhecimento. Já a forma multimídia de apresentação das aulas traz uma série de fatores que contribuem para o aprimoramento do ensino não só de botânica, mas de outras áreas. SANTOS (2014), ao trabalhar com análise dos recursos midiáticos no ensino-aprendizado de Botânica com ênfase em Educação Ambiental, constatou que $80 \%$ dos professores entrevistados afirmaram que a utilização destas mídias tem maior aceitação dos alunos, ou melhor, à familiaridade que os discentes apresentam com os recursos midiáticos e tecnológicos, motivam, trazem dúvidas e outros questionamentos, possibilitando melhorias no ensino aprendizado.

Quando em aula eram expostas as imagens das estruturas e dos espécimes vegetais das praças e locais do Município que a maioria dos alunos frequentava, isto chamou bastante atenção (Fig. 5) o que permitiu posteriormente a cada um deles a identificação do grupo vegetal que foi exposto na apresentação. STANSKI et al., (2012) trabalhando imagens de peças florais demonstraram que $15 \%$ dos alunos relataram uma significativa melhoria no domínio de terminologias botânicas mediante a associação das imagens facilitando aos alunos uma memorização rápida daquilo que era visualizado. 


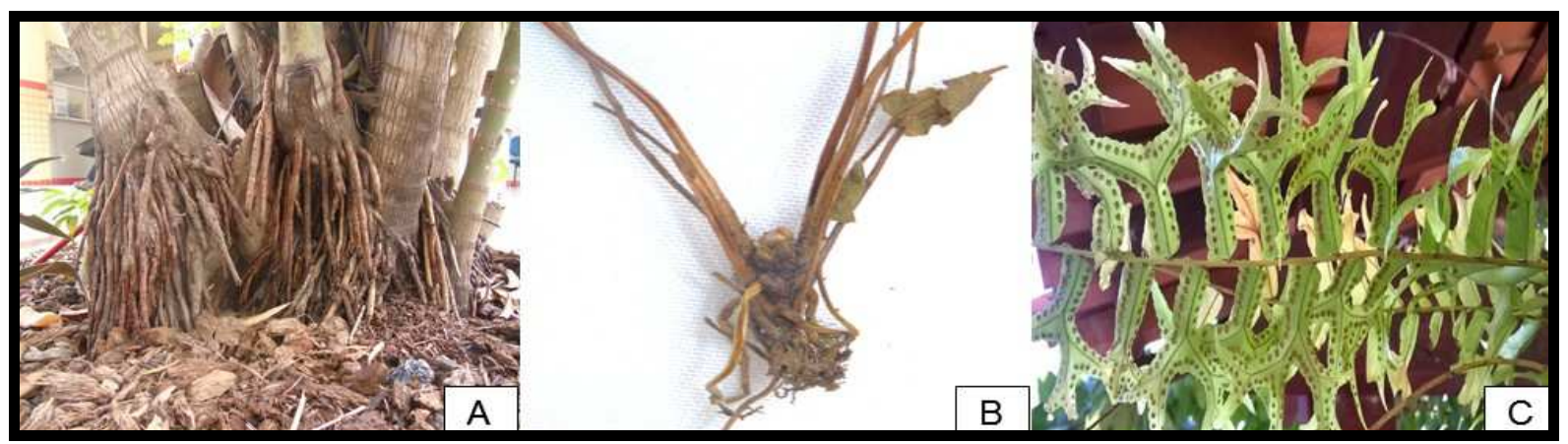

FIGURA 5. Estruturas que compões as partes da planta e estruturas reprodutivas. A. Raiz. B. Rizoma. C. Soros de uma Samambaia. Fonte: CARVALHO, S. S. 2016.

A interação dos alunos em sala de aula foi outro fator observado, pois com o desenvolver das atividades os mesmos faziam várias indagações. NERY et al., (2012) ao trabalharem com Wiki ferramenta midiática online utilizada na sala de aula sobre o conteúdo de Briófitas, observaram que tal ferramenta criou um espaço de aprendizagem e interação entre os alunos e professores no "mundo" virtual. Após as aulas utilizando o recurso Power Point os alunos foram submetidos a uma avaliação do aprendizado. Os resultados são demonstrados na figura abaixo (Fig. 6)

\section{TURMA EXPERIMENTAL}

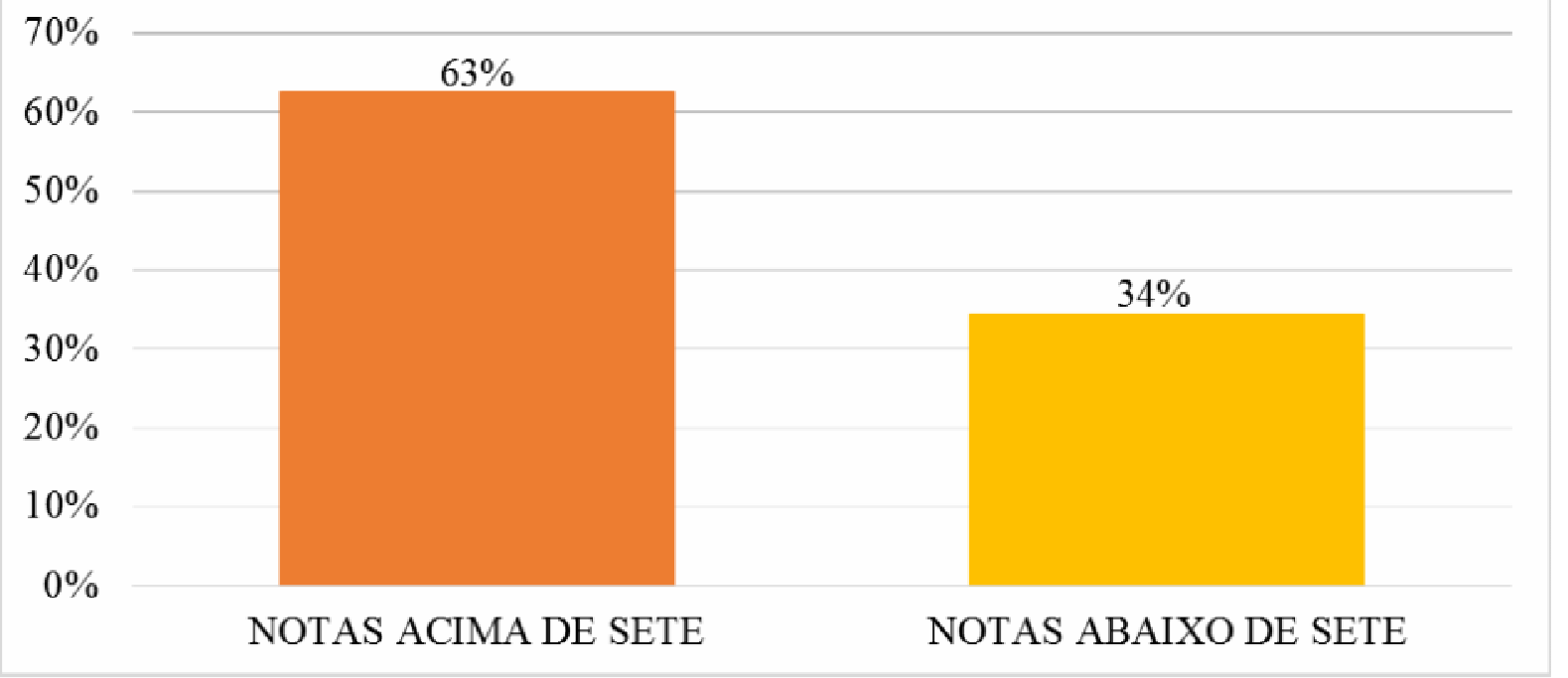

FIGURA 6. Percentual do rendimento dos alunos, através da avaliação aplicada ao final das aulas ministradas com o recurso midiático Power Point. Fonte: CARVALHO, S. S. 2016.

Observou-se que $63 \%$ dos alunos obtiveram notas acima de sete (nota aprovativa) comprovando a eficácia do uso das aulas diferenciadas com a apresentação de materiais conhecidos pelos alunos e apresentados na forma de slides. Este resultado corrobora com a pesquisa de SILVA et al., (2014) que ao utilizarem recursos midiáticos também obtiveram êxito com $63,5 \%$ dos alunos pontuando notas acima de sete.

Diante da pesquisa em pauta, percebeu-se que esse trabalho é de suma importância na contribuição de uma visão mais crítica sobre a importância do 
docente estar constantemente repensando a postura enquanto educador, devendo estar aberto a mudanças na perspectiva de poder contribuir na formação dos discentes, preparando estes para o mercado de trabalho e carreira acadêmica, mostrando que os recursos midiáticos e tecnológicos estão à disposição para serem utilizados na melhoria do ensino aprendizado. FREITAS (2015) trabalhando com ferramenta midiática através de jogos online sobre as partes da folha, salienta que através dos recursos multimídias, os alunos puderam aguçar a curiosidade sobre o conteúdo exposto e que também conseguiram fixar melhor os conteúdos propostos, mostrando que a eficácia dos recursos tecnológicos em sala de aula instiga alunos e professores na busca pela melhoria do ensino aprendizado. COSTA et al., (2012) ao utilizarem a ferramenta multimidiática (projetor multimídia) com imagens de Briófitas observaram que $69 \%$ dos discentes neste estudo também aprimoraram 0 conhecimento ao descreverem as características do grupo quanto a morfologia e estrutura.

O desenvolvimento do projeto mostrou de forma eficaz como o ensino de botânica pode ser aprimorado, pois muitas dificuldades estão vinculadas a essa disciplina e assim o ensino de botânica ganha subsídios para uma melhor prospecção no campo estudantil, visão essa que SILVA et al., (2015) têm sobre o ensino de botânica, retratando que o tema pode ser abordado de forma multidisciplinarmente e interdisciplinarmente, pelo fato de estar intimamente ligado ao cotidiano e realidade vivenciado pelos discentes.

\section{CONCLUSÕES}

O presente trabalho é de grande relevância no que se refere ao uso das tecnologias educacionais, pois permitiu aos professores aplicar metodologias que de fato tenham eficácia no processo ensino-aprendizagem. Estas ferramentas em benefício da educação e do processo ensino-aprendizado corroboram com determinados obstáculos enfrentados pelos educandos na aquisição de novos conhecimentos. Vale ressaltar que metodologias midiáticas e práticas educacionais inovadoras quebram o paradigma convencional de ensino visando sempre à melhoria da educação.

Com a disponibilidade dos slides na internet, professores e alunos terão acesso a uma nova fonte de informação com uma ferramenta de fácil manipulação, este ponto referencial trará significativas contribuições para o processo de ensino e aprendizagem, possibilitando o desenvolvimento de certas habilidades dos alunos, de um crescente interesse pela realização destas práticas de ensino.

\section{AGRADECIMENTOS}

À Universidade Estadual do Maranhão/UEMA, pela formação e fomento do projeto; à Proexae/UEMA pela concessão da bolsa de Extensão; ao Laboratório de Biologia Vegetal/LABIVE pelo apoio em todas as etapas da pesquisa.

\section{REFERÊNCIAS}

BRASIL. Parâmetros Curriculares Nacionais. MEC/SEF, 1998.

BRASIL, LDB. Lei de diretrizes e bases da educação nacional. Presidência da República Casa Civil. 1996. Disponível em: http://www.planalto.gov.br/ccivil_03/Leis/L9394.htm. Acesso em: 06/04/2016. 
BRASIL, PNLD. Guia de livros didáticos: ciências - ensino fundamental. Brasília: Ministério da Educação, Secretaria de Educação Básica, p. 144, 2014.

COSTA, M. S. F.; GOMES, M. S.; SILVA, M. J. L. A Abordagem dos Conteúdos de Botânica a partir dos Pressupostos do Ensino Médio Inovador. XVI ENDIPE Encontro Nacional de Didática e Práticas de Ensino - UNICAMP - Campinas, p. 12, 2012.

FRISON, M. D.; VIANNA, J.; RIBAS, F. K. Ensino de Ciências e Aprendizagem Escolar: manifestações sobre fatores que interferem no desempenho escolar de estudantes da educação básica. Seminário de Pesquisa em Educação da região Sul - IX ANPED SUL. p. 10, 2012.

FREITAS, C. J. O uso de jogos virtuais aplicados ao currículo de biologia do ensino médio. Universidade federal do rio grande do sul. Centro interdisciplinar de novas tecnologias da educação. Curso de especialização em mídias na educação. Porto alegre, p. 45, 2015.

GAMA, L. N.; TAVARES, C. M. M. Educação e Mídias: implicações contemporâneas no Cotidiano Acadêmico. Texto Contexto Enferm. Florianópolis, v. 24, n 2, p. 593539, 2014. Disponível em: http://www.scielo.br/pdf/tce/v24n2/pt_0104-0707-tce-2402-00593.pdf. Acesso: 08/06/2016.

JUNIOR, W. A.; BARROS, D. M. V. Objetos de aprendizagem virtuais: material didático para a educação básica. Associação Brasileira de Educação a Distância ABED. Bauru, p. 10, 2005.

KENSKI, V. M. Educação e tecnologias o novo ritmo da informação. 6a ed. Papirus, Campinas-SP, p.141, 2010.

MARTINS, E. K.; NOGUEIRA, M. K. F. S. FERREIRA, A. R.; MORALES, A. G. N. A utilização de material didático botânico no Ensino de Ciências. In: II Simpósio Nacional de Ensino de Ciência e Tecnologia, UTFPR-PR, p. 14, 2010.

MELO, E. A.; ABREU, F. F.; ANDRADE, A. B.; ARAÚJO, M. I. O. A aprendizagem de Botânica no Ensino Fundamental: dificuldades e desafios. Scientia Plena, v. 8, n. 10, p. 8, 2012.

MICROSOFT. Apostila Office Power Point 2013. 2013. Disponível em: http://201.62.79.63/ftp/programas/Unidades/apostilas/Cursos_apostilaspdf/PowerPoi nt2013/Apostilas/PowerPoint2013.pdf. Acesso em:10/03/2016.

MORAN, J. M. Ensino e aprendizagens inovadores com apoio de tecnologias. In: MORAN, J. M. Novas tecnologias e mediação pedagógica. 21a Ed. Campinas (SP): Papirus, p.11-72, 2013.

NERY, U. R. S.; LIMA, D. C. F.; PAES, L. S. A utilização de Pbworks como recurso didático para o ensino de biologia. Congresso Norte Nordeste de Pesquisa e Inovação - Ciência, tecnologia e inovação: ações sustentáveis para o desenvolvimento regional. Palmas-TO, VII CONNEPI. p.10, 2012. 
SANDERS, M. F.; SAUER, R. T. As problemáticas no uso dos recursos tecnológicos nas turmas de ensino médio na educação de jovens e adultos (EJA) nas escolas de Eunápolis/BA. 2014. Disponível em: <http://www.senept.cefetmg.br/galerias/Anais_2010/Artigos/GT7/AS_PROBLEMATI CAS_NO_USO.pdf> Acesso em: 07/05/2014.

SANTOS, F. S. A Botânica no Ensino Médio: Será que é preciso apenas memorizar nomes de plantas? In: SILVA, C. C. Estudos de história e filosofia das ciências: Subsídios para aplicação no ensino. Editora Livraria da Física. São Paulo, 2006.

SANTOS, J. R. O. Ensino de Ciências e o Meio Ambiente: uma análise do uso de recursos midiáticos sobre a temática ambiental. V Enebio e II Erebio Regional 1. Revista da SBENBIO. n. 7, p 11, 2014

SILVA, E. O.; SILVA, G. S.; CONCEIÇÃO G. M. O Uso de formas e estruturas didáticas como facilitadores no ensino de botânica. LXV CONGRESSO NACIONAL DE BOTÂNICA XXXIV ERBOT - Encontro Regional de Botânicos. Botânica na América Latina: conhecimento, interação e difusão. Salvador, 2014.

SILVA, F. S. S.; MORAIS, L. J. O.; CUNHA, I. P. R. Dificuldades dos Professores de Biologia em Ministrar aulas práticas em escolas públicas e privadas do município de Imperatriz (MA). Revista UNI. Imperatriz (MA), v. 1, n.1, p.135-149, 2011

SILVA, L. A. O Uso Pedagógico de Mídias na Escola: Práticas Inovadoras. Revista Eletrônica de Educação de Alagoas. v. 1. № 1, p. 10, 2013.

SILVA, R. F.; CORREA, E. S. Novas Tecnologias e Educação: a evolução do processo de ensino e aprendizagem na sociedade contemporânea. Educação \& Linguagem. v. 1, n 1, p. 23-35, 2014.

SILVA, T. S.; COSTA, L.K. P. F.; LIMA, R. S. Modalidades didáticas no ensino de botânica: oficinas pedagógicas como instrumento para o ensino-aprendizagem de conceitos botânicos. XIII Congresso Internacional de Tecnologia na Educação Tecnologia Educação. Tecnologia e a Escola do Futuro. P. 12, 2015

STANSKI, C.; NOGUEIRA, M. K. S.; RODRIGUES, A. R. F. Aprendizagem significativa no ensino de botânica por meio de multimodos. III Simpósio Nacional de Ensino de Ciências e Tecnologia - SINETEC. Ponta Grossa -PR. p.10, 2012.

SOUSA, D. L. S.; CARVALHO D. C.; MARQUES, E. S. A. O uso de recursos tecnológicos em sala de aula: relato envolvendo experiências do Pibid do curso de Pedagogia da UFPI. IV FIPED - Fórum internacional de Pedagogia, Parnaíba - PI/BRASIL Campina Grande, REALIZE Editora, 2012

TIMBANE, S. A; AXT, M.; ALVES, E. O Celular na Escola: Vilão ou Aliado!. Nuevas Ideas en Informática Educativa. TISE, p. 6, 2015. 